\title{
DANÇAR E BRINCAR: UMA EXPERIÊNCIA DE BALÉ COM CRIANÇAS PEQUENAS ${ }^{1}$
}

\author{
Taynara Ferreira Silva \\ Universidade Federal de Goiás, Goiânia, Goiás, Brasil. \\ Fernanda de Souza Almeida \\ Universidade Federal de Goiás, Goiânia, Goiás, Brasil. \\ Nilva Pessoa Souza \\ Universidade Federal de Goiás, Goiânia, Goiás, Brasil.
}

\begin{abstract}
Resumo
A presente pesquisa questionou a possibilidade de abordar o balé com crianças entre 4 e 5 anos de idade, matriculadas em uma academia na cidade de Inhumas (GO), por meio do lúdico. A partir da pesquisa-ação, com registro em diário de campo, estudaram-se autores que discorrem sobre o tema (HUIZINGA, 2000; KISHIMOTO, 2007; ALMEIDA, 2016), seguido da elaboração de um curso com a oferta de 15 intervenções em dança, para uma turma de baby class com 12 crianças. As vivências foram permeadas de jogos, brinquedos cantados, brincadeiras e faz de conta, como um caminho metodológico de propor a dança com a pequenada. Notou-se que as crianças aprenderam os passos do balé brincando e se divertindo, destacando o lúdico como uma estratégia interessante para as vivências em balé.
\end{abstract}

Palavras-chave: Metodologia. Prática. Balé clássico. Infância.

\section{DANCING AND PLAYING: A BALLET EXPERIENCE WITH SMALL CHILDREN}

\begin{abstract}
This research questioned the possibility of approaching the ballet with children between 4 and 5 years old, enrolled in a gym in the city of Inhumas (GO), through play. From the practical research with field journaling, we studied authors that discuss the theme (HUIZINGA, 2000, KISHIMOTO, 2007, ALMEIDA, 2016), followed by the elaboration of a course with the offer of 15 interventions in dance for a "baby class" with 12 children. The experiences were permeated by games, singing toys, child's play and pretends, as a methodological way of offering dance to the little girls. It was noticed that the children learned the footsteps of ballet playing and having fun, highlighting the playful as an interesting strategy for ballet experiences.
\end{abstract}

Keywords: Methodology. Practice. Classic Ballet. Childhood.

\footnotetext{
${ }^{1} \mathrm{O}$ presente trabalho não contou com apoio financeiro de nenhuma natureza para sua realização.
} 


\section{BAILAR E JUGAR: UNA EXPERIÊNCIA DE BALLET CON TICOS PEQUEÑOS}

\section{Resumen}

La presente investigación cuestionó la posibilidad de abordar el ballet con niños entre 4 y 5 años de edad, matriculados en una academia en la ciudad de Inhumas (GO), por intermedio de lo lúdico. A partir de la investigación-acción con registro en diario de campo, se estudiaron autores que discurren sobre el tema (HUIZINGA, 2000, KISHIMOTO, 2007, ALMEIDA, 2016), seguido de la elaboración de un curso con la oferta de 15 intervenciones en danza, para una clase de baby class con 12 niños. Las vivencias fueron impregnadas de juegos, juguetes cantados, bromas y juegos de simulación e imitación, como un camino metodológico de ofrecer la danza a los pequeños. Se ha percibido que los niños aprendieron los pasos del ballet jugando y divirtiéndose, destacando lo lúdico como una estrategia interesante para las vivencias en ballet.

Palabras clave: Metodología. Práctica. Ballet Clásico. Infancia.

\section{O balé e a criança: encontros possíveis?}

O balé é uma manifestação artística que utiliza movimentos predominantemente suaves, expressando a leveza dos corpos. Essa linguagem busca uma postura e uma organização corporais que remetem à elegância das cortes europeias, uma vez que surge dos cerimoniais e dos divertimentos da aristocracia, representando a riqueza e o poder da sociedade da época (FARO, 2011). Sua comunicação estabelece-se, frequentemente, por meio de movimentos codificados, entre eles o plie, ${ }^{2}$ tendu, ${ }^{3}$ elevé, ${ }^{4}$ que são desenvolvidos em aulas e podem ser conectados em forma de coreografias.

Nesse contexto, o balé clássico durante muitos anos vai valorizar os bailarinos solistas, o centro da cena como o lugar de destaque a ser ocupado, objetivando um corpo ideal, com capacidades físicas específicas, para uma expressividade em um único modelo geométrico, no qual as regras se definiriam pela exatidão e pela precisão de movimentos (SILVA, 2013).

Ao longo do tempo, o balé passou por revitalizações e inovações em seus figurinos, passos, escolas, metodologias de ensino, construção dramática da cena e elaborações de novos conceitos, impulsionadas pelas mudanças sociais, históricas, políticas e econômicas de cada época. Na contemporaneidade, o balé tem se reinventado, dialogando com a educação somática e oferecendo vivências que enfatizam a consciência de si, um cuidado com o posicionamento das articulações, a organização do espaço e um respeito aos diferentes corpos. Entretanto, é possível encontrar um número expressivo de locais que mantêm uma estrutura tradicional e rígida das aulas, especialmente nos projetos de contraturno de escolas de educação básica e nas etapas de iniciação à dança em algumas academias.

Neste contexto, percebe-se uma lacuna existente no ingresso da criança ao balé, nos conhecidos baby class - turmas anteriores ao estágio preliminar do ensino do balé que abrangem os pequenos de 2 a 6 anos de idade (WOLLZ, CERQUEIRA e MÜLLER, 2016) -, pois, muitas vezes, provocam uma perda de interesse e prazer pela dança, à medida que expõem a criança a uma cobrança excessiva de compromisso, padronização, disciplinarização de corpos e a sentimentos ambíguos de se sentir incluído/excluído (FELTES; PINTO, 2015).

\footnotetext{
2 Na língua francesa, a palavra plié significa dobrar. No balé, tal termo remete, usualmente,a uma flexão de joelhos para impulsionar e amortecer movimentos.

${ }^{3}$ Tendu em francês é sinônimo de esticado, gerando uma ação de estender a perna à frente, ao lado e atrás.

${ }^{4}$ Passo do balé que solicita uma elevação dos calcanhares do solo.
} 
Desse modo, para que o balé se aproxime das especificidades da infância, é importante uma abordagem que possibilite a expressão das diferentes identidades, evitando proposições nas quais os pequenos sempre se movimentam igualmente, ao mesmo tempo e dentro de um modelo normatizado e muito detalhado de posições corretas de mãos, braços, cabeças e pés.

Sob tais aspectos, segundo Almeida (2016, p. 35), a dança com a pequenada "necessita estimular a descoberta e não a padronização; a improvisação e não a repetição de movimentos previamente determinados" pelo adulto o tempo todo. O passo é inerente ao balé, mas também é interessante que as crianças tenham a possibilidade de escolher seus movimentos e objetos para descobrirem suas preferências e, principalmente, a sua dança, respeitando as individualidades e deixando de lado a intensa reprodução de ações.

Corroborando Caminada e Aragão (2006), não podemos negar os conhecimentos construídos historicamente "pelos muitos estudiosos que se debruçaram para desenvolver aquilo que conhecemos hoje como balé; contudo, na posição de educadores precisamos deixar de olhar para esse conjunto de técnicas sistematizadas como algo pronto e acabado" (CAMINADA; ARAGÃO, 2006, p. 13) e prosseguir, continuar repensando essa prática, principalmente as metodologias de abordagem com as crianças menores.

Nesse sentido, uma forma interessante de promover o contato dos pequenos com alguns fundamentos do balé é usar os princípios lúdicos, como destacou Silva (2013), Freitas (2012), Feltes e Pinto (2015), Almeida e Campos (s/d) e Nabinger (2016), no envolvimento com a musicalidade, a criatividade, a imaginação, a expressividade, a sensibilidade, o encontro com o outro e, principalmente, a descontração.

Dessa forma, este estudo questionou uma possibilidade de abordar o balé com crianças entre 4 e 5 anos de idade, matriculadas em uma academia de ginástica na cidade de Inhumas (GO), por meio do lúdico. Com isso, objetivou-se investigar, elaborar um curso e oportunizar a vivência de uma proposta de dança infantil que utilizasse jogos, brinquedos cantados e brincadeiras como um caminho metodológico de intervenção.

A presente investigação fez-se relevante para a formação docente da autora deste artigo, uma vez que foi possível experimentar novas vivências e estratégias para suas aulas, abrindo diversos caminhos para oferecer o balé às crianças, com o intuito de ir ao encontro das peculiaridades dessa etapa da vida. Este estudo proporcionou que as intervenções nessa dança tivessem uma melhor qualidade na perspectiva de mais prazer, motivação dos participantes e trouxe à pesquisadora uma identidade profissional que antes era vaga.

Desse modo, esta pesquisa pode também colaborar para a formação dos demais professores, iniciantes ou experientes na área de dança, pois, ao revelar uma possibilidade metodológica, pode inspirar e despertar o interesse por outros caminhos para abordar o balé na infância de uma maneira mais adequada. Isso porque muitos professores reproduzem as aulas como em suas vivências como bailarino, utilizando meios tradicionais de ensino, esquecendo-se da subjetividade da criança, seus interesses e curiosidades, como destaca Silva (2013).

Para acrescentar, Nabinger (2016, p.15) aponta que "o professor precisa preocupar-se com o modo pelo qual a criança aprende, muito mais do que como ele vai ensinar, buscando meios para tornar eficiente e atraente a relação ensino-aprendizagem". É nesse contexto que esta pesquisa seguiu ao se preocupar com uma das características centrais da infância (o lúdico) para pensar as práticas em dança.

Sob tais aspectos, é relevante destacar a importância de o pesquisador estudar a prática, desvendando o cotidiano em seu contexto real, dando maior visibilidade aos diversos modelos metodológicos e transpondo as paredes da universidade. 


\section{Favorecendo o encontro: caminhos metodológicos}

Para responder à problemática, partiu-se de uma abordagem qualitativa, com caráter de pesquisa-ação, buscando um olhar de dentro do problema; sob a ótica da professora e autora deste artigo, para a própria prática educativa, de maneira reflexiva, crítica e transformadora.

A escolha pela pesquisa-ação deve-se à natureza dessa investigação e ao papel desempenhado pela pesquisadora. Nesse sentido, Thiollent (1986) defende que, ao se eleger a pesquisa-ação, o pesquisador sempre trabalhará com ações devidamente planejadas, sejam elas de caráter social, educacional, técnico ou de qualquer outra natureza. No campo educacional, muitas vezes, esse tipo de pesquisa é utilizado no sentido de buscar novas possibilidades de ensino que sejam mais apropriadas para um determinado grupo.

Com isso, a pesquisa foi levada para o local de trabalho da autora deste artigo, direcionada a uma turma de balé que contou com 12 crianças entre 4 e 5 anos de idade, cujas aulas eram ofertadas duas vezes na semana com 45 minutos de duração cada uma, ao longo de 15 intervenções.

Segundo André (1995, p. 33) "a pesquisa-ação envolve sempre um plano de ação, plano esse que se baseia em objetivos, em um processo de acompanhamento e controle da ação planejada e no relato concomitante desse processo". Desse modo, elaborou-se um plano de ação que tinha como objetivo geral ampliar a conscientização do corpo das crianças, a coordenação do movimento, o equilíbrio e o ensino de alguns passos iniciantes do balé, como plié, sauté, ${ }^{5}$ passé, ${ }^{6}$ echappé, ${ }^{7}$ glissé ${ }^{8}$ tendo o lúdico como estratégia central. Partindo desses pressupostos, para cada intervenção foi elaborado um plano de aula, seguido da construção do diário de campo.

O registro em diário serviu como instrumento de coleta de dados e teve por objetivo retratar as ações de intervenção, bem como as reflexões do pesquisador, as avaliações para o planejamento das ações, evidenciado os principais apontamentos acerca da mudança de comportamento das crianças no decorrer das vivências (FLICK, 2009). Para a análise dos dados, optou-se por estabelecer um diálogo, a partir das informações contidas nos registros, com autores que pudessem fornecer elementos para discutir os resultados alcançados.

Por fim, com o intuito de proteger o bem-estar dos participantes, este estudo integrou o projeto de pesquisa trienal Dançarelando: a práxis artístico-educativo em dança com crianças, aprovado pelo Comitê de Ética e Pesquisa (CEP) sob o n ${ }^{0} 51819415.60000 .5083$. Desse modo, a instituição onde foi realizada esta investigação autorizou a realização da pesquisa por meio de um termo de anuência, assim como os responsáveis das crianças assinaram o termo de consentimento livre e esclarecido (TCLE).

\section{Quando a dança se depara com o lúdico}

Para Cipriano Luckesi (2005), uma atividade lúdica é aquela que propicia a plenitude da experiência, buscando uma entrega total: mental, emocional e física; é um momento de imersão, de mergulho na vivência; vai além do sentido mais simplista do senso comum sobre

\footnotetext{
5 Tipo de salto iniciado e finalizado por um plié.

${ }^{6} \mathrm{Na}$ língua francesa, a palavra passé significa passou. No balé, tal termo representa um movimento no qual um dos pés, encostado na perna de apoio, sobe até a altura do joelho, passando da frente para trás ou de trás para frente.

${ }^{7}$ Echappé em francês é sinônimo de escapado, que gestualmente simboliza o ato de flexionar os joelhos e arrastar as duas meias pontas pelo chão, ao mesmo tempo, à frente/trás ou ao lado.

${ }^{8}$ Passo do balé que indica escorregar/arrastar. No balé é uma extensão de perna lançada (com velocidade, firmeza e próxima ao solo).
} 
o riso e a diversão. Desse modo, o lúdico pode ser concebido como uma ação de muita seriedade para a criança, muitas vezes possuída por um impulso criador e uma inspiração livre e vigorosa.

Nesse sentido, o lúdico é particular e individual; o que é prazeroso e gera envolvimento para um pode não ser o que motiva o outro. Com isso, pensar uma intervenção que dialogue com o lúdico é, antes de mais nada, olhar sensivelmente para o grupo e constantemente (re)pensar as proposições, diversificando-as.

Em relação à dança, Almeida (2016) comenta que o acolhimento do lúdico como uma estratégia para mediar a dança com as crianças pequenas demonstra-se viável devido ao seu caráter dinâmico, criativo e atraente, sem ser rotineiro. Dessa forma, utilizar elementos do lúdico, como jogos, brincadeiras e brinquedos cantados em aulas de balé, é essencial para a criança, pois se torna um grande atrativo, possibilitando que ela crie, exerça autonomia e interaja com seus colegas e educadores.

A brincadeira e o jogo possibilitam várias oportunidades para que a criança crie e imagine situações do seu cotidiano, permitindo que ela participe do processo de criação e recriação da atividade, bem como da dança.

Conceituar o jogo e brincadeira não é uma tarefa fácil, como explica Kishimoto (2007), pois essas palavras podem apresentar diversos aspectos conceituais. Souza (2011) revela que a brincadeira é uma atividade livre e espontânea, que não pode ser delimitada, sem tempo e espaço predeterminado, com um fim em si mesma. Já o jogo, na concepção de Huizinga (2000), é produzido pelo meio social e envolve o prazer, o caráter não sério, a liberdade, a separação dos fenômenos do cotidiano, as regras, o caráter fictício ou representativo e sua limitação no tempo e no espaço.

Huizinga (2000), ao tratar das relações entre o jogo e as artes, deixa clara uma ligação direta entre ambos por meio da ação interpretativa, do seu caráter físico ligado à performance e ao gestual e ao "voo pelos espaços de que a música e a poesia são capazes" (p. 120). O autor ainda complementa:

\footnotetext{
quanto a este aspecto a situação da dança é muito especial, pois é ao mesmo tempo musical e plástica: musical porque seus elementos principais são o ritmo e o movimento, e plástica porque está inevitavelmente ligada à matéria. [...] A dança é uma criação plástica como a escultura, mas apenas por um momento. Tem em comum com a música, que a acompanha e que é sua condição necessária, o fato de depender de sua capacidade de repetição. (HUIZINGA, 2000, p. 120).
}

Para ele, "a dança é uma forma especial e especialmente perfeita do próprio jogo" (HUIZINGA, 2000, p. 120)

A estátua é um exemplo de jogo, no qual as crianças começam a dançar enquanto a música toca e, quando a música para, elas fazem "estátuas". Uma outra maneira de mediar esse jogo é a estátua montada: um grupo dança e outro grupo observa e, quando a música para de tocar, o grupo que estava observando remodela as estátuas que estavam dançando.

Além disso, visualizou-se no jogo morto, vivo ou enterrado, proposto por Almeida (2016, p. 65), uma maneira pertinente para ensinar o elevé e o plié, passos principais do balé, adaptando-o da seguinte forma: inicialmente as crianças são organizadas em círculo e, quando a professora fala vivo, todas realizam o elevé (levantar o corpo e apoiar na meia ponta dos pés com os joelhos estendidos); quando a professora diz morto, as crianças executam um plié (uma semiflexão dos joelhos) e, quando ela fala enterrado, as crianças se sentam no chão com as pernas flexionadas para trás.

Outro elemento lúdico muito utilizado neste estudo foram os brinquedos cantados, que se consolidam por meio da linguagem artística da música. Por sua aproximação com a dança, foi dado um enfoque a eles durante as intervenções. 
Segundo Paiva (2000), os brinquedos cantados retratam nossa cultura, são sempre dinâmicos e funcionais e de fácil compreensão e assimilação. Ademais, são compreendidos como formas lúdicas de brincar com o corpo, com músicas e sons, a partir da linguagem. Eles associam o movimento do corpo e a expressão vocal em uma única prática, possibilitando às crianças a expressão corporal, comunicativa e afetiva sob a forma de manifestações de alegria, batida de palmas, gestos e até mesmo o gritar.

O brinquedo cantado Fui no Itororó, ${ }^{9}$ por exemplo, foi relacionado ao balé, com todos em roda cantando, enquanto um participante por vez ia ao centro dançar. Quando a música terminava, a criança que estava no meio da roda fazia uma reverancé ${ }^{10}$ e convidava outra a entrar. Neste estudo, na maioria das vezes, esse brinquedo cantado foi utilizado para finalizar a aula, para que as crianças colocassem em prática alguns passos que foram utilizados nas vivências.

Por fim, o faz de conta, elemento central na infância, também foi evidenciado nas intervenções. Este caracteriza-se por ser uma ação que destaca a situação imaginária na qual a criança pode fantasiar, imitar e incorporar papéis. Almeida (2016, p. 64) faz uma aproximação entre o faz de conta e a dança, colocando-o como uma interessante proposição para a mediação da dança com a pequenada, uma vez que pode contribuir para a ampliação das possibilidades do movimento, a dramaticidade do gesto, a criação, a sensibilidade e o sentido da vivência.

Um exemplo da conexão entre faz de conta e o balé foi a elaboração da história Caminho de pedras da bailarina. Primeiramente, foi sugerido que as crianças fechassem os olhos e imaginassem um caminho cheio de pedras preciosas e cristais. Quando abriram os olhos, havia na sala um caminho com papéis coloridos, E.V.A., ${ }^{11}$ bambolês e fitas de cetim. Coletivamente criou-se a história para aquele cenário, no qual individualmente elas executaram alguns passos do balé como sauté, echappé, gallop ${ }^{12}$ e skip, ${ }^{13}$ transpondo os materiais.

\section{Na trilha da ação dançante}

A partir dos aprofundamentos e das reflexões em torno dos conceitos anteriormente apresentados, somados à experiência profissional da autora, elencaram-se os conteúdos do balé mais indicados para oferecer às crianças de 4 e 5 anos de idade, associando-os ao lúdico e aos princípios metodológicos destacados por Almeida (2016) em livro. Essa pesquisadora não discorre sobre o balé; desse modo, realizaram-se adaptações e transposições para responder à pergunta da pesquisa.

Os conteúdos priorizados para as vivências em balé foram os passos básicos tendu, plié, elevé, sauté, skip, echappé e outros. Também foram utilizados os elementos da dança, como as ações corporais (deslocar, parar, saltar, girar, torcer, encolher, esticar, rolar, entre outros), peso, equilíbrio e espaço (ALMEIDA, 2016).

Segundo a autora citada, o peso "é um dos fatores de movimento da teoria de Laban e pretende transmitir a intenção do sujeito na ação". Ele é classificado em duas qualidades: leve e firme. "Os movimentos leves necessitam de uma menor força em sua execução e revelam

\footnotetext{
${ }^{9}$ Música de domínio público do cancioneiro popular infantil brasileiro.

${ }^{10}$ É um movimento específico do balé para reverenciar; uma forma de agradecimento, curvando o corpo à frente, que frequentemente é utilizada ao final das aulas e apresentações de dança.

${ }^{11}$ Em português, é a sigla de acetato-vinilo de etileno, uma espuma sintética muito usada em artesanato e para confeccionar materiais infantis e escolares.

${ }^{12} \mathrm{Na}$ língua francesa, tal termo significa passo de cavalo. É um salto que acontece elevando em passé uma perna por vez, sendo que no ar os dois pés se encontram.

${ }^{13}$ Skip é um tipo de salto realizado alternando-se as pernas, uma vez que o pé encosta no joelho oposto.
} 
suavidade e leveza [...]. O peso firme é o oposto e requer maior grau de contração muscular para o movimento acontecer" (ALMEIDA, 2016, p. 86). No balé, utilizam-se ambos os pesos; o leve está presente, na maioria das vezes, nos braços, em suas movimentações suaves de port de bras, ${ }^{14} \mathrm{e}$ o firme se materializa nas pernas, com os grand battements, ${ }^{15}$ tendus e glissés.

Nas aulas de balé, uma maneira de conceituar e vivenciar o peso leve é utilizar balões e fitas com imagens de nuvens, folhas ao vento e plumas. $\mathrm{O}$ firme pode ser apresentado com exercícios de resistências ao ar, como se as crianças andassem empurrando a lama.

Já o equilíbrio é a percepção do eixo corporal e das bases de sustentação do corpo. Existem três tipos de equilíbrio e todos eles são evidenciados na dança. O equilíbrio estático consiste na inibição voluntária do movimento, que no balé pode ser representado pelo elevé e pelo passé. O equilíbrio dinâmico se refere ao controle do corpo em situação de deslocamento no espaço, envolvendo, por exemplo, o couru, ${ }^{16}$ e, por fim, o equilíbrio recuperado, que provoca a estabilização após saltos (ALMEIDA, 2016). Todos eles são relacionados à postura, que, segundo Mattos e Neira (2004), é o posicionamento do corpo, algo também bastante enfatizado no balé.

Almeida (2016) destaca "o espaço como um elemento importante para a dança. Essa linguagem se utiliza necessariamente dele, construindo-o e ressignificando-o. É no espaço que o corpo se situa e onde se desenvolvem os movimentos expressivos" (p. 41). Sob tais aspectos, o espaço se divide em diversos conceitos, entre eles, distância, direções, progressão no espaço e níveis.

A distância refere-se a perto e longe. Nas aulas de balé, pode ser sugerido que as crianças dancem bem próximas ou bem afastadas umas das outras ou de algum objeto. As direções consistem em esquerda e direita, frente e trás, em cima e embaixo, podendo ser trabalhados no balé com a realização do port de bras. Já a progressão no espaço é, segundo Laban (1978), o deslocamento do ponto de apoio do corpo em diferentes trajetórias - linha reta, circular, ziguezague, entre outras -, promovendo desenhos no solo. Um exemplo para a realização desse elemento é a execução de movimentos de deslocamento como o couru e o skip, nas diferentes trajetórias, utilizando objetos para a marcação no chão.

Os níveis tratam da altura no espaço em que as ações acontecem e se classificam em alto, médio e baixo. No balé, utiliza-se com maior enfoque o nível alto, pois destaca a postura ereta e os saltos; o nível médio também é empregado, mas com pouca frequência; o nível baixo não é praticamente aproveitado no balé. Contudo, neste curso de dança, todos os níveis foram vivenciados, mesmo não sendo muito utilizados no balé, pois auxiliam na ampliação e na diversificação das experiências de movimento na infância.

Como estratégias para a mediação de tais conceitos associados à consciência do corpo, usufruiu-se essencialmente dos jogos, brincadeiras, brinquedos cantados e faz de conta, discutidos anteriormente.

Além do lúdico, o curso foi embasado nos preceitos de Almeida (2016), que recomenda que a dança com crianças enfatize a interação social, a improvisação, a imitação e a apreciação estética. A interação social é uma forma de sociabilização, de estar com o outro; é relevante para favorecer a cooperação, a solidariedade e o respeito à diversidade. Nas intervenções de balé desta pesquisa, a interação social foi estimulada por meio de atividades em duplas, trios ou quando foi pedido que elas decidissem algo em conjunto, como escolher o jogo, compor coletivamente a história, entre outros.

A improvisação, segundo Almeida (2016, p. 68), "é compor, rearranjar e mesclar movimentos do repertório motor baseados em algum tema, motivação, objeto, música,

\footnotetext{
${ }^{14}$ Termo que remete a uma movimentação dos braços.

${ }^{15}$ Em francês, refere-se a uma grande batida, na qual uma das pernas eleva-se, de maneira controlada, o mais alto possível, mantendo o resto do corpo alinhado.

${ }^{16}$ Couru expressa correndo. É uma execução rápida de um passo.
} 
parceiro, entre outros", criando novas gestualidades. Nesse sentido, deve-se considerar a importância dela para o grupo etário, uma vez que contribui com a criatividade, a autonomia, a identidade e a tomada de decisão.

A imitação é também uma estratégia metodológica pertinente à abordagem da dança com crianças, contudo, deve ser empregada com cautela e consciência. Sem um objetivo claro, ela pode transformar-se em uma reprodução vazia que pouco irá acrescentar à pequenada. Sob tal aspecto, Almeida afirma que

\begin{abstract}
é necessário que imitar não seja uma ação reprodutiva sem sentido, que impeça os pequenos de reelaborarem suas experiências como uma manifestação pessoal. Um exemplo de como trabalhar a imitação e a reelaboração dos movimentos é a utilização de DVDs de espetáculos de dança. A criança aprecia, reconhece os signos desta linguagem artística, imita os artistas e depois reorganiza os movimentos a sua maneira, surgindo uma nova composição. (ALMEIDA, 2013, p. 44).
\end{abstract}

Por fim, a apreciação estética é um momento no qual as crianças assistem a algo proposto pelo professor, como um vídeo ou coreografias dançadas ao vivo. Nesta pesquisa, elas assistiram principalmente às colegas, em momentos de improvisação, sendo organizadas em dois grupos, o que foi seguido por uma conversa sobre a experiências.

Com isso, a partir de todos os elementos e conceitos apresentados, elaborou-se o curso de balé infantil, com uma construção semanal dos planos de aula, apoiados pelas constantes reflexões ao longo do processo.

\title{
(Mu)Dança e (transform)ação
}

As 15 intervenções ocorreram entre os meses de agosto a outubro e, como a professora/pesquisadora estava mediando as vivências para essa turma desde o início do ano, não houve a necessidade de uma adaptação entre ela e as crianças. Entretanto, houve uma alteração na proposta metodológica das aulas para responder à pergunta de pesquisa; com isso, os pequenos demonstraram um pouco de dificuldade de compreender e aceitar que na dança também poderiam brincar.

Ao longo do processo, foi possível notar todos se divertindo bastante. Além das usuais histórias de princesas, castelos, magia e flores, associadas à realização de passos específicos, brincou-se de pega-pega e imitação de animais, algo pouco habitual em uma aula de balé.

Em especial, no segundo dia de intervenção, foi mediado o faz de conta criado pela professora/pesquisadora com os pequenos, Animal da floresta, que consistia em sugerir que as crianças imaginassem estar em uma floresta, transformando-se nos diferentes animais citados na história. Nessa proposição, as crianças imitaram os animais como desejaram, rastejando, rolando e engatinhando, ações corporais raramente vivenciadas no balé.

Tal procedimento deixa de lado, momentaneamente, as peculiaridades dessa dança para atender às necessidades e aos interesses do universo infantil sobre o encantamento pelos elementos da natureza, bem como de um desenvolvimento integral favorecendo a ampliação das experiências de movimento, capacidades comunicativas e perspectivas sobre si e o meio. A esse respeito, Freitas (2012, p. 2) observa que, "quando gozamos da liberdade de brincar com o corpo, ganhamos em criatividade, autonomia, confiança e nos relacionamos melhor com o outro".

Sobre o jogo, na $12^{\mathrm{a}}$ intervenção, foi mediada a vivência do Siga o mestre, que consistiu em escolher uma criança aleatória para ficar à frente do grupo para comandar a dança do restante dos colegas. Para que todos vivenciassem a experiência de estar à frente, a professora/pesquisadora permaneceu atenta para alternar o mestre. 
O siga o mestre foi um sucesso, todos ficam empolgados para chegar a vez e isso fez com que eles se mantivessem animados com a vivência. Percebi que as crianças permaneceram felizes de poder comandar a turma. Dessa forma, notei o que elas estão aprendendo durante as intervenções de balé, pois quando elas fazem sozinhas e sem um direcionamento, mostram o que está ficando do curso. (Diário de campo, 19/10/16).

Ao imitar umas às outras, as crianças ampliaram suas experiências corporais e a coordenação do movimento, utilizaram o espaço nas diferentes direções, progressões e níveis, acompanhando a música, criando gestualidades e improvisando. Tal jogo pode despertar a autonomia, uma vez que há a possibilidade de escolher como irão comandar os movimentos.

No $13^{\circ}$ encontro, o jogo Coelho saiu da toca foi adaptado para Bailarina saiu da casa, utilizando vários bambolês que ficaram espalhados pela sala. Em seguida, foi proposto que as crianças passeassem pela floresta fazendo skip ou gallop e, quando dissessem Bailarina saiu da casa, deveriam entrar no bambolê. Para modificar a vivência, foram retirados alguns bambolês para que várias crianças ficassem juntas na mesma casa, favorecendo a cooperação e a interação, até que permaneceram apenas três casas e todas as crianças dentro delas.

Essa vivência foi surpreendente; alguns participantes nunca tinham feito essa atividade, outros já conheciam, mas a logística de tirar os bambolês e todos ficarem em um só foi muito divertida. Eles tiveram que se abraçar e eu pude perceber que executaram o passo do balé que foi proposto. (Diário de campo, 03/10/16).

Sobre o brinquedo cantado, no $6^{\circ}$ encontro, este foi ofertado para motivar exercícios de alongamento, por meio das cantigas da Dona Aranha e Borboletinha. ${ }^{17}$ Nesse ensejo, a professora/pesquisadora relatou perceber que, ao cantar e dançar, tal elemento lúdico possibilitou a interação social, a musicalização e a dissociação do movimento, aspectos relevantes para o contato com o balé.

Todavia, além do conhecimento dos passos dessa dança de maneira prazerosa, as atividades lúdicas auxiliaram também, no processo de aprendizado, a memorização e o ensaio da coreografia para o espetáculo de final de ano. No jogo 1, 2, 3, ao enunciar cada número, a professora/pesquisadora favoreceu diversas formas de organização pelo espaço, como círculo, coluna e fila intercalada, todas posições da coreografia. Essa estratégia a fez registrar em diário de campo a percepção de um melhor aproveitamento no ensaio, sem desmotivar os pequenos. Em outro jogo ela registrou:

essa atividade eu criei para que as crianças decorassem seus lugares da coreografia. Ela consistiu em separar a turma em 3 grupos no qual o grupo 1 seriam as minhas filhas, o grupo 2, filhos da auxiliar V, e o grupo 3, filhas da auxiliar A. A partir disso, foi solicitado que todos fechassem os olhos para que as "mamães" mudassem de lugar e ao sinal iriam correndo, como bailarinas, fazer um círculo com a sua respectiva mãe. E assim repetimos várias vezes. Fiquei contente ao perceber que as crianças gostaram dessa vivência, pois uma grande dificuldade que eu tenho é com o desinteresse ao ensaiar para o espetáculo. (Diário de campo, 26/09/16).

Ao final de todas as intervenções, era oferecido um momento de improvisação e apreciação, pois, nos planos de aulas, esses conteúdos caminhavam juntos. Nesse momento, as crianças escolhiam e realizavam movimentos aprendidos em suas vivências anteriores, sejam eles passos de balé ou qualquer outro gesto que estivesse na memória corporal delas. Este era um momento em que os pequenos se sentiam livres para dançar a dança deles. E, ao

\footnotetext{
${ }^{17}$ Músicas de domínio público do cancioneiro popular infantil brasileiro.
} 
mesmo tempo em que as crianças estavam dançando, seus colegas permaneciam apreciando. Na sequência, ocorria um diálogo entre todos.

Ao longo do processo, notou-se que as crianças realizaram os movimentos com maior interesse e dedicação e que as atividades de velocidade foram idolatradas pelos participantes. Eles correram, gritaram e se alegraram.

A respeito do espetáculo, o pai de uma das crianças afirmou notar sua filha mais entusiasmada para ir às aulas de balé, uma vez que, antes dessa proposta lúdica, ela estava desmotivada. Dessa forma, compreendeu-se que os resultados estavam aparecendo e se consolidando.

\section{Re-flexões}

Os caminhos adotados para alcançar o questionamento desta pesquisa sobre a possibilidade de abordar o balé com crianças entre 4 e 5 anos de idade, por meio dos jogos, brincadeiras, brinquedos cantados e faz de conta, percorreram o estudo de autores que discorrem sobre o tema, bem como a elaboração e a aplicação de um curso de balé no entendimento do lúdico.

A intervenção no campo foi intensa e produtiva. Visualizou-se que a proposta construída estava inserida na perspectiva acima citada e se concretizou como um caminho metodológico interessante para as intervenções de balé. A professora/pesquisadora observou que as crianças aprenderam os passos do balé brincando e se divertindo, além de ter expandido a atenção e o interesse da pequenada pelas atividades.

Em alguns momentos, no decorrer do processo, o universo das princesas e dos seres mágicos deixou de ser empregado; havia temas de animais, estátua, pega-pega, entre outros. Tal estratégia pode favorecer a construção e o despertar de diferentes maneiras de viver a feminilidade, aproximando-se das discussões atuais sobre o papel/identidade da mulher na sociedade (não mais de frágil e submissa).

Dessa forma, o balé pode aguçar a curiosidade e possibilitar o interesse de outras crianças em relação a personalidades diversas: aquela que gosta da bruxa, que brinca de bola, que tem casca de ferida, marca de vacina, bigode de groselha e medo de vertigem, contrariando a Ciranda da bailarina, de Chico Buarque.

Por fim, ao refletir sobre a experiência, a professora/pesquisadora declarou notar uma maior segurança e clareza em relação às necessidades da infância. Anteriormente, suas expectativas residiam na realização ideal dos movimentos próprios do balé, constantemente frustradas pelas crianças, que preferiam permanecer correndo ou gritando. Nesse sentido, ela destacou ter descoberto sua identidade docente, uma vez que se encantou pela abordagem lúdica, criando vivências e histórias para que as aulas continuassem motivantes e próximas ao universo infantil.

Ao longo do processo, ficou nítido que a prática e a pesquisa sobre a prática são fontes inesgotáveis de possibilidades e experimentações; cada turma, docente, contexto geram uma combinação peculiar e inusitada, contestando a produção de modelos ou receitas de bolo.

Espera-se, a partir deste estudo, despertar o interesse de outros professores atuantes do balé infantil pelo lúdico e seus elementos na mediação com as crianças. Que os professores possam também investigar suas práticas e descobrir caminhos que motivem as bailarinas.

\section{Referências}

ALMEIDA, F. de S. Que dança é essa?. São Paulo: Summus, 2016. 
ALMEIDA, M. P. de; CAMPOS, M. F. A Pedagogia do balé clássico para crianças e a construção dos saberes. Rio grande do Norte, s/d. Disponível em: <http://www.editorarealize.com.br/revistas/fiped/trabalhos/Trabalho_Comunicacao_oral_idin scrito_2013_0f3125295bed192d1883d943aaf7835e.pdf>. Acesso em: 26 nov. 2016.

ANDRÉ, M. de. Etnografia da prática escolar. Campinas: Papirus, 1995.

CAMINADA, E.; S., V. M. A. de S.. Programa de ensino para um curso regular de ballet clássico - uma proposição. Rio de Janeiro: Editora UniverCidade, 2006. 150 p.

FARO, A. J. Pequena história da dança. 7. ed. Rio de Janeiro: Zahar, 2011.

FELTES, A. F.; PINTO, A. da S. Balé e educação infantil: possibilidades metodológicas. Revista Conhecimento Online, Novo Hamburgo, a. 7, v. 2, p 13-26, 2015. Disponível em: <https://www.google.com.br/search?q=BAL\%C3\%89+E+EDUCA\%C3\%87\%C3\%83O+INF AN-

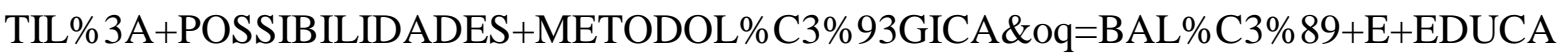
$\% \mathrm{C} 3 \% 87 \% \mathrm{C} 3 \% 83 \mathrm{O}+\mathrm{INFANTIL} \% 3 \mathrm{~A}+\mathrm{POSSIBILIDADES}+\mathrm{METODOL} \% \mathrm{C} 3 \% 93 \mathrm{GICA} \& \mathrm{aq}$ $\mathrm{s}=$ chrome..69i57j69i65.814j0j7\&sourceid=chrome\&ie=UTF-8>. Acesso em: 26 nov. 2016.

FLICK, U. Desenho da pesquisa qualitativa. Porto Alegre: Artmed 2009.

FREITAS, A. C. do N. Balé e brincadeiras de roda: aprendendo o erudito com o popular. VII CONNEPI, Palmas -TO, 2012. Disponível em: <http://propi.ifto.edu.br/ocs/index.php/connepi/vii/paper/view/1709/1039>. Acesso em: 5 fev. 2019.

HUIZINGA, J. Homo Ludens: o jogo como elemento da cultura. São Paulo: Perspectiva, 2000 .

KISHIMOTO, T. M. Jogo, brinquedo, brincadeira e a educação. 10. ed. São Paulo: Cortez, 2007.

LABAN, R. Domínio do movimento. 5. ed. São Paulo: Summus, 1978.

LUCKESI, Cipriano Carlos. Ludicidade e atividades lúdicas: uma abordagem a partir da $\begin{array}{llll}\text { experiência } & \text { interna. } & 2005 . & \text { Disponível }\end{array}$ <http://www.luckesi.com.br/artigoseducacaoludicidade.htm>. Acesso em: 20 maio 2016.

MATTOS, M. G. de; NEIRA, M. G. Educação Física infantil: construindo o movimento na escola. Guarulhos: Phorte Editora, 2004.

NABINGER, A. D. Sensibilização para a técnica clássica: conhecendo aulas de baby class. $25^{\circ}$ seminário nacional de arte e educação. Anais... Monte Negro: Editora da Fundarte. V. 1, n. 2016.2 Disponível em: <http://seer.fundarte.rs.gov.br/index.php/Anaissem/article/view/369>. Acesso em: 25 nov.

PAIVA, I. M. R. de. Brinquedos cantados. 2000. 37 f. Dissertação (Mestrado) Universidade Federal de Santa Catarina, Florianópolis, 2000. Disponível em: 
<https://repositorio.ufsc.br/bitstream/handle/123456789/78240/175386.pdf?sequence=>. Acesso em: 7 jul. 2016.

SILVA, R. P. da. A importância do lúdico no desenvolvimento de crianças praticantes de balé clássico (baby class): Uma forma de educar. 2013. Monografia - Universidades Federal do Rio Grande do Norte, Natal, 2013. Disponível em: <https://monografias.ufrn.br/jspui/bitstream/123456789/1308/1/Silva_Raniele_Polyane_da>. Acesso em: 25 nov. 2016.

SOUZA, N. P. Pesquisa e ensino em jogos e brincadeiras. Goiânia: UFG/FEF/Ciar. FUNAPE, 2011.

SOUZA, R. C. A importância das atividades lúdicas no desenvolvimento técnico infantil. 2007. Monografia (Pós-Graduação "Lato Sensu" em Psicomotricidade) - Universidade Cândido Mendes, Rio de Janeiro, 2007.

THIOLENT, M. Metodologia da pesquisa-ação. São Paulo: Cortez Editora, 1986.

WOLLZ, L. E. B.; CERQUEIRA, J. C.; MÜLlER, R. F. As pequenas bailarinas do baby class: construções do feminino no ensino do balé. Demetra, v. 11, n. 3, p. 745-762, 2016. Disponível em: $<$ http://www.epublicacoes.uerj.br/index.php/demetra/article/view/22504/18423\#.WBtu7vkrLIU>. Acesso em: 3 nov. 2016.

Recebido em: 05/12/2010

Revisado em: 23/04/2018

Aprovado em: 04/10/2018

Endereço para correspondência:

tay.danca@gmail.com

Taynara Ferreira Silva

Faculdade de Educação Física e Dança

Campus samambaia

Av. Esperança, s/n - Chácaras de Recreio Samambaia

74690-900 - Goiânia - GO, Brasil 